\title{
Habermas, Rorty e o Pragmatismo Americano
}

\author{
Filipe Carreira da Silva
}

\section{RICHARD RORTY: IRONIA LIBERAL E ESPERANÇA SOCIAL}

“Todo poeta que não é de todo irracional compara, aprimora e argumenta até encontrar a formulação correcta do que deseja dizer. Não seria maravilhoso se esse processo desempenhasse um papel também nas ciências?" Paul Feyerabend

"Aquilo que esperamos dos cientistas sociais é que actuem como intérpretes daqueles em relação aos quais não estamos seguros de como falar com eles. Isto é a mesma coisa que esperamos dos nossos poetas, dramaturgos e romancistas". Richard Rorty

R ichard Rorty, o célebre filósofo americano, é uma figura central no morte da crença em um certo tipo de fazer ciência ("verificacionista" no século XIX, "falsificacionista" no século XX). Isto é tanto mais significativo quanto termos em conta que o projeto filosófico rortyano se

DADOS - Revista de Ciências Sociais, Rio de Janeiro, Vol. 49, n-1 1, 2006, pp. 99 a 117. 
assume explicitamente como o herdeiro da primeira corrente filosófica nascida nos Estados Unidos, o pragmatismo. Neste artigo, pretendo discutir o pragmatismo filosófico americano enquanto um universo discursivo em que se entrecruza o liberalismo pós-moderno de Rorty e a teoria social de Jürgen Habermas. Este posicionamento estratégico do pragmatismo permitir-me-á, argumento, fazer luz sobre as limitações da estratégia de construção teórica adotada por Habermas. Em particular, a minha tese é a de que o pragmatismo filosófico americano constitui um objeto que resiste ativamente aos esforços de reconstrução racional empreendidos por Habermas desde meados dos anos 1960 até os dias de hoje. Caso esta tese demonstre ser válida, a tentativa de Habermas em complementar a teoria marxista com os princípios democráticos do pragmatismo de Dewey e Mead no âmbito de uma "grande narrativa" terá de ser reequacionada; a alternativa, em meu entender, passará antes por uma apropriação do legado pragmatista que respeite a natureza processual e orientada para a resolução de problemas concretos desse paradigma. Tal alternativa é por mim concebida enquanto um "pluralismo dialógico" de pendor historicista.

Pode descrever-se o neopragmatismo de Rorty como sendo movido por dois interesses fundamentais. Por um lado, afastar a herança kantiana (bem como a filosofia analítica de Russell e Moore, em um primeiro momento, e dos positivistas lógicos entretanto emigrados para os Estados Unidos, em um segundo momento), e, com ela, a preocupação epistemológica. Por outro lado, abandonar uma filosofia que já não cumpre os objetivos a que se propôs em favor de uma pós-filosofia em que a preocupação pela objetividade dê lugar à preocupação pela solidariedade. Rorty associa este tema da solidariedade ao da esperança social, uma espécie de otimismo quanto ao nosso destino comum. De fato, em Contingência, Ironia e Solidariedade, o autor afirma que, de acordo com a concepção do liberal irônico, "a solidariedade humana não é uma questão de partilhar uma verdade comum ou um objectivo comum, mas sim uma questão de partilhar uma esperança egoísta comum, a esperança de que o mundo de cada um [...] não será destruído" (Rorty, 1994:126).

Ainda nessa obra, Rorty compara a sua própria posição epistemológica com as propostas de Thomas Kuhn e de Quentin Skinner. Isto acontece quando Rorty assinala que a nossa atenção deve ser dirigida não para frases isoladas, mas para os vocabulários em que estas são formuladas, em uma postura anti-reducionista claramente influenciada pelo 
holismo semântico de Quine. Negando o caráter pretensamente volitivo ou racional da escolha de um vocabulário, Rorty sugere que o ato de seleção de uma linguagem em detrimento de outra tem uma natureza social, coletiva ou holista. "Tal como Kuhn defende em 'The Copernican Revolution"," Rorty observa, "nós não decidimos [...] que a Terra não era o centro do Universo. [...] Em vez disso, [...] os europeus deram consigo próprios a falar de um modo que tomava como certas estas teses interligadas. [...] Não deveríamos, nestas matérias, procurar quaisquer critérios de decisão dentro de nós, nem no mundo" (idem:27). Esta rejeição de um critério racional que permita reconstruir a história do pensamento científico em Rorty é em tudo semelhante à tese de Kuhn, segundo a qual a evolução da atividade científica se pauta por longos períodos de continuidade (a "ciência normal") interrompidos esporadicamente por momentos de ruptura (as "revoluções científicas"): para Kuhn, tal como para Rorty, são as condições sociais de produção científica que determinam em larga medida a evolução da ciência. No entanto, em Rorty essa tese epistemológica surge englobada em um projeto filosófico mais amplo em que a recuperação do pragmatismo clássico americano (nomeadamente, na sua versão deweyana) surge como alternativa à filosofia analítica.

Antes de mais, como se define o pragmatismo segundo Rorty? Como explica em Consequências do Pragmatismo, em primeiro lugar, é ao pragmatismo de John Dewey e William James que Rorty vai buscar inspiração para romper com "a tradição epistemológica kantiana" (Rorty, 1982:231). O mesmo é dizer: James e Dewey "pediram-nos que abríssemos mão da neurótica demanda cartesiana da certeza que tinha sido um dos resultados da assustadora nova cosmologia de Galileu [...]" (idem:232). Em segundo lugar, o pragmatismo à la Rorty é uma espécie de "antiessencialismo aplicado a noções como 'verdade', 'conhecimento', 'linguagem', 'moralidade', e objectos semelhantes de teorização filosófica" (idem:233). Em terceiro, o pragmatismo pode ser caracterizado como postulando a não-diferenciação epistemológica entre a verdade acerca do que deve ser e aquela acerca do que é, a não-diferenciação metafísica entre fatos e valores, a não-diferenciação metodológica entre moralidade e ciência. Em outros termos, Rorty procura sublinhar que a busca epistemológica da essência da ciência é um exercício em vão. Pelo contrário, toda a investigação científica ou moral deve consistir em uma deliberação a respeito das vantagens relativas das várias alternativas disponíveis em cada momento. Rorty procura, em suma, recuperar o ideal socrático da conversação contra o mito platô- 
nico da razão enquanto um estado de consciência iluminado a que chegamos por via de determinados procedimentos. A epistemologia não seria, segundo este ponto de vista, mais do que a procura de tais procedimentos (idem:235). Por último, o pragmatismo para Rorty sublinha a irredutível contingência dos pontos de partida das minhas investigações. Sempre que iniciamos uma investigação só devemos esperar orientação dos nossos colegas de trabalho, uma espécie de constrangimento conversacional. Ou seja, advoga a inutilidade da idéia de que um método científico rigoroso ou uma linguagem neutra e clara bastem para que os objetos se tornem disponíveis para a mente humana.

Segundo um ditado espanhol, "os caminhos fazem-se caminhando". De fato, para Rorty, foi Galileu o primeiro viajante que trilhou esse caminho chamado modernidade. Foi ele quem primeiro pensou ter identificado a linguagem da natureza, em um projeto em que foi seguido por Descartes, Locke, Berkeley, Hume e Kant, e que se prolongou até ao século XX, com o positivismo lógico. Rorty lamenta que tão poucos pensadores tenham sugerido que

"[t]alvez a ciência não tenha um segredo de sucesso - que não há explicação metafísica ou epistemológica ou transcendental da razão por que o vocabulário de Galileu funcionou tão bem até aqui, tal como não há uma explicação da razão por que o vocabulário da democracia liberal funcionou tão bem até hoje" (idem:268).

Significativamente, Rorty considera que Kuhn e Dewey se encontram entre estes raros casos.

No caso de Kuhn, é sublinhado o fato de que evita um evolucionismo teleológico em direção a um fim chamado "correspondência com a realidade". O paralelismo entre estas duas posições foi, aliás, já por nós salientado aquando da exposição do debate entre Kuhn e os seus críticos. Subscrevendo a noção kuhniana de ciência normal enquanto uma atividade de resolução de enigmas, Rorty sugere que aquilo que os cientistas normalmente fazem é usar "os mesmos métodos óbvios e banais que todos nós usamos em todas as actividades humanas. Conferem exemplos com critérios; remendam os contra-exemplos quanto baste para evitar a necessidade de novos modelos; experimentam vários palpites, formulados no jargão corrente [...]" (idem:269). Ao reter das teses de Kuhn a importância do vocabulário usado em cada teoria (responsável pela incomensurabilidade que as separa), bem como a noção de "resolução de enigmas" como atividade científica fundamental (lem- 
bre-se que a ciência extraordinária ou revolucionária é, pelo menos na primeira versão do argumento de Kuhn, extremamente rara), Rorty recupera do debate epistemológico dos anos 1960 dois elementos basilares para a sua própria posição epistemológica - a linguagem, cuja contingência sublinha, e um método científico, mais próximo da vida cotidiana do que dos manuais científicos.

Mas é em Dewey que Rorty encontra o seu grande inspirador. Em rigor, é a abordagem deweyana à ciência social que mais fascina Rorty, uma vez que se define precisamente pelo sublinhar da importância das narrativas e dos vocabulários, em detrimento da objetividade das leis e teorias científicas. Aliás, é Dewey quem inspira não só Rorty, mas também Kuhn quando estes enjeitam a possibilidade de se conhecer a Natureza tal como é. Por outras palavras, quando em Logic. The Theory of Inquiry, Dewey critica Kant por este concluir que a realidade percepcionável, embora necessária, "prejudica completamente o conhecimento das coisas tais como 'realmente' são" [...]" (Dewey, 1938:518), defende uma filosofia que abandone a intenção de continuar a procurar "as coisas tal como realmente são" - ou seja, antiessencialista. Uma filosofia que, apesar de não ser rotulada explicitamente de pragmatista, é "totalmente pragmática" (idem:iv). Por outro lado, é também uma filosofia preocupada com os fenômenos da linguagem, entendida como o meio através do qual a cultura existe, é transmitida e pode ser guardada para futuras discussões. Neste sentido, a linguagem constitui "o registo que perpetua as ocurrências e que as torna passíveis de virem a ser avaliadas pelo público" (idem:20). Em rigor, este escrutínio público é o que define o próprio conhecimento, comprovando a relação umbilical, bem pragmatista, entre a linguagem e a racionalidade humana: " $\mathrm{O}$ conhecimento deve ser definido em termos de inquirição, e não o contrário, quer em termos particulares, quer em termos universais" (idem:21).

A leitura que Rorty faz de Dewey leva-o a declarar que "[s]e, como Dewey, virmos os vocabulários como instrumentos para fazer frente às coisas mais do que como representações das naturezas intrínsecas destas" (Rorty, 1982:275), então poderemos evitar a oposição, característica da forma de pensar moderna, entre um método explicativo (para explicar o comportamento de uma pessoa) e um método compreensivo (para compreender a sua natureza). A posição epistemológica de Rorty decorre desta última observação. Tendendo a concordar com a posição hermenêutica, desde que não comece a "traçar uma distinção de prin- 
cípio entre homem e natureza, anunciando que a diferença ontológica dita uma diferença metodológica" (ibidem), Rorty considera que ser interpretativo ou hermenêutico não implica a adoção de um método particular. Pelo contrário, Rorty atribui à hermenêutica uma função de procura inventiva de um vocabulário inicial, a utilizar nas nossas investigações, o que implica o abandono do vocabulário que usualmente utilizamos. É neste sentido que Rorty sugere que se deixássemos de lado a metáfora da linguagem da natureza, bem como o vocabulário de representação que a acompanha, "como Kuhn e Dewey sugerem que podemos - então não acharíamos misteriosas a linguagem ou a mente, nem particularmente perigosos o 'materialismo' ou o 'behaviorismo'" (Rorty, 1982:279). Daqui à defesa da contigüidade entre os discursos científico e literário é um pequeno passo:

"Quando a noção de conhecimento como representação é abandonada [...], as linhas entre romances, artigos de jornal, e investigação sociológica tornam-se difusas. As linhas entre objectos de estudo são traçadas por referência a preocupações práticas concretas, mais do que a putativos estatutos ontológicos" (idem:280).

É justamente este último ponto que Habermas critica em O Discurso Filosófico da Modernidade (1985), rejeitando igualmente a interpretação rortyana da tradição pragmatista. Este é, aliás, o ponto de partida da seção que se segue.

\title{
HABERMAS E O NEOPRAGMATISMO DE RORTY
}

\author{
"A rejeição do autor é positivismo". \\ (Jürgen Habermas, tradução do autor)
}

O confronto entre Habermas e Rorty é particularmente importante para a minha argumentação por uma razão fundamental. Refiro-me à idéia de que, do conjunto de teorias filosóficas que Habermas se propõe reconstruir de forma a definir a sua própria posição, o pragmatismo filosófico americano parece constituir um "paradigma" que resiste ativamente a essa intenção. Pondo de lado a forma como outras tradições intelectuais selecionadas por Habermas podem resistir ao processo de reconstrução racional levado a cabo por este último, creio poder, todavia, afirmar o seguinte. No caso concreto da corrente filosófica pragmatista, parece-me razoável sugerir que nos encontramos perante uma perspectiva que, pela voz de outros intérpretes que não Habermas (veja-se o caso de Quine, Kuhn, ou Rorty), se caracteriza precisa- 
mente pela rejeição de iniciativas desse tipo (representacionistas, diria Rorty). Esta seção compreenderá dois momentos: em primeiro lugar, exporei a teoria habermasiana dos interesses cognitivos, que caracteriza a sua posição epistemológica na década de 1960, altura em que Habermas começa a se apropriar de alguns dos contributos do pragmatismo americano; em segundo lugar, descreverei os traços essenciais do debate entre Habermas e Rorty, cujas implicações apontam para o questionamento das possibilidades de sucesso da estratégia habermasiana de construção teórica.

Em meados dos anos 1960, década de profundas mudanças sociais e culturais, Habermas viu-se confrontado com o desafio de responder à crise em que se encontrava a chamada "teoria crítica". Fundada décadas antes por figuras como Theodor Adorno, Max Horkheimer e Erich Fromm, a teoria crítica, entre os anos 1930 e os 1960, tinha sabido manter-se na vanguarda mais inovadora da teoria social e política. Porém, na década de 1960, o projeto emancipatório da teoria crítica parecia dar mostras de estar a perder fulgor. As principais dificuldades diagnosticadas por Habermas são, em primeiro lugar, os fundamentos normativos da teoria crítica, em segundo lugar, a sua noção de verdade, e, por último, a subvalorização das tradições da democracia e do Estado constitucional (Habermas, 1986:98). Para responder a estas dificuldades, Habermas considera que a aproximação à filosofia analítica (análise lógica e da linguagem) e a reconstrução do materialismo histórico através da crítica a Marx são os passos incontornáveis. A ancoragem da teoria crítica no potencial emancipatório do projeto da modernidade é, para Habermas, uma opção de fundo. Isto por duas ordens de razões: por um lado, para preservar-se das soluções positivistas de perfil conservador e, por outro, para evitar as soluções relativistas que haviam abandonado a convicção na função emancipatória da razão humana. $\mathrm{Na}$ agenda de Habermas, a prioridade consiste em refundar a teoria crítica com um modelo de racionalidade e de ação humana que permita, a um tempo, criticar os aspectos patológicos da modernidade sem abandonar as suas conquistas mais valiosas. Daí o abandono da via epistemológica em favor da viragem para a linguagem, uma mudança de estratégia que analisarei mais à frente.

Antes, porém, gostaria de discutir a forma como Habermas supera as dificuldades encontradas pela teoria crítica nos anos 1960. Ao criticar Marx por ter caído em um positivismo latente ao conferir uma importância quase exclusiva ao trabalho, na sua concepção de natureza hu- 
mana e de praxis, Habermas apresenta uma alternativa: a distinção entre trabalho e interação, sendo esta última considerada a base fundamental das atividades comunicativas e simbólicas que constituem a vida social (Habermas, 1968). Esta crítica a Marx estava relacionada com uma proposta epistemológica que define o essencial do pensamento habermasiano sobre este tema, a teoria dos interesses cognitivos. Esta noção de interesses do conhecimento remonta à formulação positivista da epistemologia, enquanto uma tarefa de reconstrução lógica, que pressupõe um sujeito cognoscente universal. Este último tem a sua atividade de produção de conhecimento validada como resultado de um processo de verificação (ou falsificação, dependendo das versões de positivismo em questão) das explicações cujo principal critério é a sua forma lógica. Aos olhos dos críticos do positivismo, isto não é mais do que uma espécie de essencialismo lógico. Neste contexto de crítica a Marx e ao positivismo, qual foi a alternativa encontrada por Habermas? - o pragmatismo clássico de Peirce e Dewey é a resposta.

Em Knowledge and Human Interests (1968), Habermas recorre à teoria da ciência pragmatista de forma a propor uma noção de ciência que a concebe não apenas como uma forma de conhecimento, mas também como uma forma de atividade social. A necessidade de auto-reflexão da ciência, implicando o estudo das condições sociais de produção científica e a negação de que a atividade científica possa ser reduzida a um método ou tipo de explicação particular, é aquilo que Charles Sanders Peirce, no campo das ciências naturais, e Wilhelm Dilthey, no domínio das ciências humanas, nos ensinaram. Com o intuito de evitar a tese positivista de que o conhecimento possui apenas um interesse (empírico-analítico, que procura explicar os fenômenos da natureza através de leis invariáveis), Habermas identifica três interesses cognitivos, ou três formas que o nosso interesse científico em lidar com o mundo pode assumir. Em primeiro lugar, existe um interesse empírico-analítico baseado no desejo de controlar a natureza física (em uma primeira versão) e social (em uma formulação posterior). Em segundo, pode-se identificar um interesse histórico-hermenêutico que visa a interpretar e entender qualitativamente a natureza externa e interna. Porém, Habermas critica este tipo de conhecimento por pretender ser universal e auto-suficiente, como ficou claro no seu debate com HansGeorg Gadamer. Em terceiro lugar, existe um interesse crítico-emancipatório que pretende transformar a consciência humana da realidade de forma a emancipar o ser humano. No essencial, esse interesse emancipatório constitui um caso especial do interesse hermenêutico, em que 
a atitude face aos significados, em vez de meramente os descrever e compreender, assume uma forma crítica.

É neste sentido que Habermas recorre à psicanálise de modo a ilustrar a lógica por detrás das funções críticas do conhecimento. Assim, tal como Freud enceta uma reconstrução narrativa das histórias de vida individuais, Habermas, por analogia, sugere que uma teoria social crítica reconstrua narrativamente o processo de autoprodução da sociedade, guiada precisamente pelo interesse crítico-emancipatório. Em termos metodológicos, esta crítica da ideologia assume a forma de uma "comunicação sistematicamente distorcida", uma noção que remete para o fato de que o neurótico (tal como o oprimido) sofre de um distúrbio comunicativo interior e inconsciente, que apenas um terapeuta pode resolver. Todavia, Habermas reconhece não só que a correlação entre os diferentes tipos de conhecimento e as várias disciplinas é problemática (Habermas, 1986:193), como esta noção de comunicação sistematicamente distorcida, associada à teoria dos interesses cognitivos, deve ser abandonada em favor do estudo das condições mais gerais de comunicação intersubjetiva, que podem servir de critério a possíveis desvios.

Isto significa que a partir do final dos anos 1960, início dos anos 1970, Habermas abandona essa estratégia de justificação epistemológica do interesse de conhecimento crítico-emancipatório, e a idéia de fundamentar a investigação social em uma teoria da linguagem ${ }^{1}$ começa a dominar a sua teoria de uma pragmática universal e de reconstrução racional-é como se o pensamento de Habermas operasse, tal como a filosofia, uma viragem para a linguagem. Até ao final da década de 1970, Habermas inicia uma nova etapa na sua carreira que culmina, já no início da década seguinte, na publicação da monumental obra em dois volumes Theorie des Kommunikativen Handelns (1981). Esta mudança é motivada pela convicção de que "eu já não acredito na epistemologia enquanto a via regia", na medida em que uma teoria crítica da sociedade necessita de "fundamentos substanciais" (Habermas, 1986:150). Essa teoria da competência comunicativa é uma tentativa para justificar a pretensão de erigir a linguagem enquanto a estrutura privilegiada para se aceder à emancipação, através da reconstrução da base normativa da fala enquanto um sistema de pretensões de validade universais e necessárias. Em rigor, e como explica Habermas, a designação proposta de uma "pragmática universal" para o programa de pesquisa que visa a reconstruir as bases de validade universal do discurso reme- 
te diretamente para a sua intenção fundamental, a saber: a de identificar e reconstruir as condições universais da possibilidade de entendimento mútuo (Habermas, 1976:5).

Em termos genéricos, pode-se afirmar que essa pragmática formal se distingue da lingüística semântica pelo fato de estudar não frases ou orações, mas sim proposições ou elocuções, e da sociolingüística porque estas proposições são estudadas como sendo independentes dos contextos específicos onde são produzidas. No centro da teoria da ação comunicativa e da análise habermasiana sobre a racionalidade comunicativa, encontra-se a tese de que os atos de fala invocam vários tipos de pretensão de validade:

"Irei desenvolver a tese de que qualquer sujeito que actue comunicativamente deve, ao pronunciar qualquer acto discursivo, mobilisar pretensões universais de validade e assumir que elas serão acolhidas. [...] $\mathrm{O}$ acordo baseia-se no reconhecimento das pretensões de validade correspondentes de compreensibilidade, verdade, sinceridade, e retidão" (idem:2-3).

Habermas, deste modo, propõe-se a analisar as características formais dos processos cotidianos de comunicação lingüística com vista ao entendimento mútuo de forma a comprovar a asserção de que existe uma ligação entre a linguagem e as várias dimensões de validade. A função constitutiva desta pragmática formal consiste, pois, em identificar e reconstruir as condições universais para um entendimento mútuo. Daqui decorre que o tipo de ação cujo propósito seja alcançar esta compreensão mútua se assuma como o fundamental.

Deste modo, a teoria da ação comunicativa assenta, não só mas também, em uma teoria reconstrutivista que procura identificar os pressupostos universais da comunicação cotidiana das sociedades modernas: a pragmática formal cumpre precisamente esta função. Na medida em que pode ser descrita como uma análise quase-transcendental ${ }^{2}$ que pretende reconstruir o conhecimento pré-teórico e implícito que possibilita os processos práticos de entendimento comunicativo, essa pragmática formal se distingue da empírica por esta última se preocupar não com a reconstrução das competências comunicativas humanas universais, mas com a descrição e análise de elementos específicos da prática comunicativa lingüística. Por outro lado, esta pragmática formal é pragmática na medida em que analisa o uso da linguagem, nomeadamente os atos de fala ou proposições, ao contrário da lingüística se- 
mântica que estuda as propriedades de frases isoladas (Cooke, 1994). Esta pragmática formal pode, por conseguinte, ser entendida enquanto uma parte essencial da teoria crítica de Habermas dado que sobre ela assenta a sua teoria sociológica da ação comunicativa.

Em suma, podemos concluir esta análise ao papel que a problemática epistemológica desempenha no projeto habermasiano de uma teoria crítica da sociedade com duas idéias fundamentais. Em primeiro lugar, e como conseqüência do falibilismo que sempre caracterizou as suas propostas epistemológicas, Habermas defende que a base última do discurso científico não é uma verificação factual ou uma lógica formal, mas um processo de argumentação: "A filosofia pós-empiricista da ciência deu-nos boas razões para acreditar que o instável acordo racionalmente motivado entre os participantes na argumentação é a nossa única fundamentação - em questões de física não menos do que nas de moralidade" (Habermas apud Morrow, 1994:157).

Em segundo lugar, e como observa Redondo, The Theory of Communicative Action, mais do que um livro acabado, é sobretudo uma espécie de história interna dos problemas centrais na filosofia e teoria sociológica contemporâneas (Redondo, 1987:11). Ou seja, e tal como Habermas observa, na história do pensamento sociológico (Marx, Durkheim, Weber, Parsons) podemos encontrar um problema recorrente - como conciliar o paradigma dos sistemas e o paradigma da ação? A sua resposta a este problema consiste em relacionar os dois paradigmas entre si, objetivando explicar como o sistema econômico capitalista destrói as condições necessárias à reprodução simbólica do "mundo da vida" (Lebenswelt) (Habermas, 1986:91). É por esta razão que o projeto de Habermas constitui um esforço sistemático e continuado de procura de uma justificação teórica para uma teoria social cujo interesse fundamental é, hoje como ontem, crítico e emancipatório, e por isso mesmo, irredutivelmente moderno.

A aproximação de Habermas ao pragmatismo americano fá-lo partilhar uma intuição fundamental com Rorty, apesar da distância que separa a forma como estes autores olham para o legado pragmatista. Tal intuição remete para a convicção de que a vida coletiva depende de formas vulneráveis de comunicação, recíprocas, inovadoras e produto da livre vontade das partes. Apesar de reconhecer que partilha esta intuição fundamental com Rorty, Habermas (1985), em O Discurso Filosófico da Modernidade, rejeita aquilo que considera ser uma perspectiva con- 
textualista da linguagem influenciada pela Lebensphilosophie na versão nietzschiana. Pensando ter identificado uma intenção de nivelamento entre literatura e filosofia em Rorty, Habermas compara o fluxo de interpretações presente em todas as esferas da vida cultural com a história da ciência de Kuhn: "O fluxo das interpretações pulsa, como a história da ciência de Kuhn, ritmadamente, entre revolucionamento e normalização da linguagem" (idem:195). Ou seja, para Habermas, Kuhn e Rorty são dois exemplos de uma certa forma de interpretar o pragmatismo que ele não pode subscrever: "Vemos assim como o pathos nietzschiano de uma filosofia da vida virada para o plano linguístico ensombra as sóbrias opiniões do pragmatismo" (idem:196). Dada a sua importância, prometo ao meu leitor voltar a esta posição nas considerações finais deste artigo.

A esta crítica, responde Rorty, em "A Ciência Natural é uma Espécie Natural?", sublinhando a relação existente, em seu entender, entre o pragmatismo e o romantismo. Neste sentido, a racionalidade não é nem o uso de uma faculdade mental chamada "razão", nem um método particular, constituindo "simplesmente uma questão de ser aberto e curioso, e de confiar na persuasão em vez da força" (Rorty, 1988:399-400). Noutros termos, contra a predileção de Habermas pela razão, contrapõe Rorty uma preferência pela liberdade, e em particular pela liberdade de pensamento e de comunicação. Tal posição é inaceitável aos olhos de Habermas. Para este autor, o sublinhar da contingência da linguagem faz-nos esquecer o elemento essencial da ação comunicativa, ou seja, a ação humana cujo objetivo é o entendimento mútuo através da troca de argumentos - a "força efectiva do contrafactual, a qual se faz sentir nos pressupostos idealizantes da acção comunicativa" (Habermas, 1985:196). Isto porque Rorty, tal como Heidegger, Adorno e Derrida, ainda luta contra os conceitos de "teoria", "verdade" e "sistema" "que, porém, há mais de 150 anos que pertencem ao passado" (Habermas, 1999:199n). É por esta razão que Habermas pensa que Rorty tem que recorrer à noção de uma linguagem ideal "que não exige interpretação, de que não nos podemos distanciar, que não pode ser ridicularizada pelas gerações vindouras. É a esperança de um vocabulário que é intrinsecamente e auto-evidentemente final, não apenas o vocabulário mais completo e produtivo que criámos até ao momento" (Rorty apud Habermas, 1999:199n).

Habermas rejeita tal idéia de um vocabulário que se explica a si mesmo, fechado e definitivo, que não requer ou permite qualquer comen- 
tário. A sua proposta, que aspira à verdade, transcendendo assim o tempo e o espaço, embora consciente de que esta aspiração é formulada em um contexto particular, o que implica a possibilidade da sua revisibilidade, assenta sobre uma noção crucial - "A consciência falibilista das ciências também já alcançou a filosofia" (Habermas, 1985:199n). Este falibilismo antipositivista (ou pós-positivista) de que fala Habermas é um traço que, como vimos, o acompanha desde o início da sua carreira. Um outro traço, talvez mais importante ainda, que marca o percurso intelectual de Habermas reenvia à sua insistência em dialogar com referências teóricas de modo a ir formando a sua própria posição. Se tais referências se localizam em um passado distante, como é o caso de um Aristóteles ou de um Hegel, ou se são seus contemporâneos, como é o caso de Rawls ou de Rorty, pouco importa. O relevante é, em minha opinião, a disponibilidade revelada por Habermas em levar a noção de "diálogo" a sério. Mais do que uma concepção reguladora das suas propostas teóricas, a idéia de "diálogo" constitui um traço constitutivo da sua estratégia de construção teórica. Acontece, porém, e como tentei demonstrar neste artigo, que a forma como Habermas enceta estes diálogos enfrenta algumas dificuldades. É justamente com uma reflexão sobre estas últimas que gostaria de terminar.

\section{CONSIDERAÇÕES FINAIS}

Se existe um quadro civilizacional que configura os propósitos teóricos de Habermas, esse quadro é o da modernidade ocidental. É neste contexto que devemos compreender a preocupação fundamental da sua teoria da sociedade - a explicação e a crítica do sistema econômico capitalista através de uma análise às suas conseqüências no plano do "mundo da vida". Em meu entender, o projeto de Habermas caracteriza-se por uma continuidade de fundo (quanto às premissas) e uma evolução constante (quanto ao grau de sofisticação teórica). Como tentei demonstrar ao longo deste artigo, a estratégia de reconstrução racional de várias teorias filosóficas e sociológicas pode ter os seus méritos discutidos se selecionarmos uma dessas correntes, o pragmatismo, e verificarmos como esta última, de acordo com outras interpretações (maxime a sugerida por Rorty), se caracteriza justamente pela rejeição da possibilidade de reconstrução racional. É como se o objeto da reconstrução de Habermas se recusasse activamente a ser alvo de tal reconstrução.

Com efeito, as reconstruções racionais que Habermas leva a cabo das propostas dos seus interlocutores são, a meu ver, tão profícuas quanto 
funcionais à sua própria estratégia. Se, por um lado, a forma como Habermas reconstruiu o legado pragmatista vem constituindo uma fonte de inspiração para toda uma geração de cientistas sociais e políticos fora do contexto norte-americano, por outro, não deixa de ser verdade que tal reconstrução parece não respeitar alguns dos princípios centrais do paradigma pragmatista. Refiro-me concretamente ao pronunciado pendor historicista e anticartesiano que encontramos em autores como Dewey e Mead, e que decorre da influência que autores como Aristóteles e Hegel exerceram sobre o pragmatismo americano (sobretudo sobre a sua versão nominalista, já que o "pragmaticismo" de Peirce resulta de uma outra linhagem). É justamente este o motivo que leva Rorty a associar pragmatismo ao romantismo alemão: a rejeição do universalismo abstrato e de uma concepção pura da razão humana, mais próximas de Kant e do liberalismo, é, aos olhos deste neopragmatista, uma implicação necessária do neo-hegelianismo naturalista de Dewey (e Mead, acrescentaria eu).

Uma alternativa às reconstruções racionais de Habermas é, em minha opinião, olhar para o passado das ciências sociais enquanto um repositório de tesouros que só podem ser resgatados se respeitarmos a sua natureza. Doutra forma, se violarmos a sua integridade impondo a nossa própria agenda e grelha de interpretação, estes tesouros permanecerão no passado, ficando nós apenas com os "conceptual survivors" de que falava MacIntyre no seu After Virtue (1981). Ou seja, a alternativa que proponho consiste em reconstruir de forma historicamente sensível os legados que a história das ciências sociais nos deixou. O rigor de uma reconstrução histórica permite-nos evitar anacronismos como os de atribuir a um autor do século XVI uma intenção própria do século XXI. Só deste modo, creio, podemos entrar em diálogo com os nossos antepassados dispostos a ouvir o que os textos que nos deixaram nos têm para dizer. Só assim poderemos aprender com o passado por forma a não só ver reforçadas as nossas conviç̧ões, como também vê-las questionadas por experiências ou argumentos entretanto esquecidos; neste último caso, se formos capazes de modificar as nossas posições por termos sido confrontados com um argumento convincente de um antepassado nosso, estaremos a beneficiar o mais possível de uma leitura historicista da história das ciências.

Claro que uma postura presentista como a de Habermas e tantos outros tem também as suas vantagens, nomeadamente a proficuidade que só a reflexão normativa sobre os problemas do nosso tempo pode garan- 
tir. Noutros termos, não estou a sugerir que se substitua a construção teórica por reconstruções historicamente sensíveis do passado. A minha proposta vai antes no sentido de se construir propostas teóricas à luz de problemas presentes com base em leituras historicamente sustentáveis dos nossos antecessores. Ou seja, ir buscar ao passado não as soluções dos nossos problemas (estaríamos, neste caso, a cair na falácia presentista de procurar no passado aquilo que só existe no presente), mas a inspiração que a resolução exemplar de problemas no passado nos pode dar para a resolução dos nossos próprios problemas. A responsabilidade pela resolução dos problemas do nosso tempo é nossa e só nossa; dialogando com os nossos antecessores, podemos, isso sim, ganhar uma maior distância crítica em relação às nossas crenças e aprender com os erros e as descobertas daqueles que nos antecederam. Esta posição é, em minha opinião, não somente mais consonante com os ensinamentos dos pragmatistas clássicos, como também teoricamente menos problemática do que a adotada por Habermas. A principal dificuldade que Habermas enfrenta é a de poder ficar fechado no presente, refém das suas próprias conviç̧ões e interesses teóricos, incapaz portanto de aprender tanto quanto poderia com a extensa galeria de autores que convoca nos seus escritos.

O exemplo que decidi tratar neste artigo é, deste ponto de vista, inequívoco. É ponto assente que as interpretações sugeridas por Habermas de autores como Dewey e Mead merecem o nosso maior respeito e admiração. No caso de Mead, por exemplo, e como argumentei noutros textos (como em Silva, 2004), Habermas é tão-somente um dos mais brilhantes intérpretes de Mead, tendo sido um dos principais responsáveis pela inclusão do autor de Mind, Self, and Society (1934) no cânone da sociologia. A sua tese de que o pragmatismo intersubjetivo de Mead foi o pioneiro na transição do paradigma da consciência para o paradigma da linguagem é, ainda hoje, 30 anos volvidos após a sua publicação, uma referência incontornável para quem quer que estude as relações entre o "eu" e a sociedade em que desenvolve a sua ação. Porém, aquilo para que Rorty nos alerta não é menos relevante. Como tentei demonstrar ao longo deste artigo, Rorty chama a nossa atenção para outros aspectos da tradição pragmatista que Habermas considera ficarem aquém das "sóbrias opiniões" dessa corrente teórica. Não creio poder acompanhar Habermas nesta posição. Em meu entender, o antifundacionalismo de Rorty, a sua rejeição de uma concepção representacionista da verdade, a sua crítica ao racionalismo cartesiano, bem como os seus apelos para uma defesa "ironista" da liberdade, são pro- 
postas tão inspiradas no universo discursivo pragmatista quanto as de Habermas. A proposta que aqui defendo aponta, por conseguinte, para um "pluralismo dialógico", historicamente sensível e que não menospreza a criatividade que caracteriza a reflexão teórica.

Tal pluralismo é, porém, incompatível com a estratégia de construção teórica de Habermas. Longe de defender uma síntese operada por um filósofo solitário, ainda que amante fiel do diálogo intelectual, eu gostaria de sugerir um outro caminho, por sinal já trilhado pelos pragmatistas. A noção ideal sugerida por Peirce de uma "comunidade de cientistas" cuja rede de comunicação se estabelece com base no melhor argumento, mais tarde recuperada por Mead e Dewey no âmbito de uma teoria radical da democracia, parece-me ser uma via mais promissora. Uma via dialógica que, ouvindo o maior número de perspectivas possível, nos permita beneficiar das vantagens que só a intersubjetividade garante, a saber, o confronto das nossas opiniões com as dos nossos pares, quer sejam eles cientistas ou cidadãos. Tal pluralismo dialógico, caso adequadamente complementado pelo rigor que só a reconstrução historicista dos contributos dos nossos antepassados assegura, parece ter duas vantagens importantes. Se, por um lado, o seu caráter pluralista garante a contribuição do maior número de perspectivas, por outro, o seu caráter dialógico garante que estas serão efetivamente respeitadas. Não enfrentaria, portanto, o problema de ver um objeto de estudo resistir ativamente aos nossos esforços de reconstrução; pelo contrário, o historicismo que advogo garante-nos que os nossos objetos de estudo ficam à distância imposta pelas nossas capacidades de interpretação.

A cisão sugerida por Merton entre teoria e história da teoria é, à luz deste pluralismo dialógico que aqui proponho, errônea. Pelo contrário, a história da teoria constitui um complemento valioso da construção teórica; o diálogo com os nossos antecessores, desde que respeite aquilo que eles realmente quiseram dizer, é uma fonte valiosa de ensinamentos. Um outro reside na nossa capacidade de criatividade. Novamente, opto pela tradição pragmatista. Ao invés do elitismo da concepção sugerida por Nietzsche do "génio criativo", os pragmatistas sublinham o caráter irredutivelmente democrático da criatividade, entendida enquanto uma capacidade humana de resolução de problemas concretos com recurso à imaginação: penso que esta concepção democrática de criatividade constitui uma via bem mais promissora. É, pois e para terminar, um pluralismo dialógico a perspectiva que defendo, de pendor historicista, assente na capacidade humana para a criativi- 
dade. Uma proposta inspirada nos escritos dos autores pragmatistas, construída por referência às propostas de alguns dos meus pares mais ilustres, mas pela qual apenas o autor destas linhas é responsável.

(Recebido para publicação em setembro de 2005) (Versão definitiva em janeiro de 2006)

\section{NOTAS}

1. Já existente, embora de forma embrionária, em Knowledge and Human Interests, onde Habermas observa, por exemplo, que "a gramática dos jogos de linguagem associa símbolos, ações e expressões. Estabelece esquemas de interpretação do mundo e da interação. As regras gramaticais estabelecem as condições para uma intersubjetividade aberta entre indivíduos socializados" (Habermas, 1972:92).

2. Quase-transcendental porque, como observa Maeve Cooke, "Habermas retém a linha universalista de questionamento da filosofia transcendental enquanto destranscendentaliza o modo de procedimento" (Cooke, 1994:168). 


\section{REFERÊNCIAS BIBLIOGRÁFIAS}

COOKE, M. (1994), Language and Reason. A Study of Habermas's Pragmatics. Cambridge, MIT Press.

DEWEY, J. (1938), Logic. The Theory of Inquiry. New York, Henry Holt and Company.

HABERMAS, J. (1972) [1968], Knowledge and Human Interests. London, Heineman. . (1968), Técnica e Ciência como Ideologia. Lisboa, Dom Quixote.

. (1976), What is Universal Pragmatics?, in J. Habermas (org.), Communication and the Evolution of Society. Cambridge, Polity Press.

. (1985), “Excurso sobre o Nivelamento da Diferença Genérica entre Filosofia e Literatura", in O Discurso Filosófico da Modernidade. Lisboa, Dom Quixote.

. (1986), Autonomy and Solidarity. Interviews with Jürgen Habermas. London, Verso.

. (1999), "Richard Rorty's Pragmatic Turn”, in M. Cooke (ed.), On the Pragmatics of Communication. Cambridge, MIT Press.

MACINTYRE, A. (1981), After Virtue. Notre Dame, University of Notre Dame Press.

MEAD, G. H. (1934), Mind, Self, and Society. Chicago, Chicago University Press.

MORROW, R. (1994), Critical Theory and Methodology. London, Sage Publications.

REDONDO, M. J. (1987), “Introduccion”, in J. Habermas (org.), La Lógica de las Ciencias Sociales. Madrid, Tecnos.

RORTY, R. (1982), Consequências do Pragmatismo. Lisboa, Instituto Piaget.

. (1988), “A Ciência Natural é uma Espécie Natural?”, in M. M. Carrilho e J. Sàágua (eds.), Epistemologia: Posições e Críticas. Lisboa, Fundação Calouste Gulbenkian. . (1994) [1989], Contingência, Ironia e Solidariedade. Lisboa, Editorial Presença.

SILVA, F. C. (2004), Virtude e Democracia. Um Estudo sobre Ideias Republicanas. Lisboa, Imprensa de Ciências Sociais. 


\begin{abstract}
Habermas, Rorty, and American Pragmatism

This article has two main objectives: 1) to compare how two of the most influential contemporary thinkers, Richard Rorty and Jürgen Habermas, relate to the legacy of American philosophical pragmatism and 2) to use this case to illustrate a meta-theoretical proposal of mine. The Rorty/Habermas comparison will allow me to present what I refer to as "dialogical pluralism", that is, a theoretical and methodological perspective which, inspired by the American pragmatism of Dewey and Mead, refuses to adopt the separation between theory and history of theory. On the contrary, the dialogical pluralism that I propose conceives social sciences' past as a repository of forgotten treasures that must be urgently reconstructed in order to better solve the problems of our time.
\end{abstract}

Key words: Habermas; Rorty; dialogical pluralism; pragmatism

\title{
RÉSUMÉ
}

Habermas, Rorty et le Pragmatisme Américain

Dans cet article, on vise deux objectifs: le premier, c'est de comparer comment deux des plus influents penseurs du temps présent - Richard Rorty et Jürgen Habermas - se rattachent au legs du pragmatisme philosophique américain; le second, à partir de ce cas, est d'illustrer une proposition de nature métathéorique: le rapprochement Rorty/Habermas peut permettre de présenter ce qu'on nomme ici "pluralisme dialogique", c'est-à-dire une perspective théorico-méthodologique qui, inspirée du pragmatisme américain de Dewey et Mead, refuse la distinction entre théorie et histoire de la théorie. Au contraire, le pluralisme dialogique conçoit le passé des sciences sociales comme un réservoir de trésors oubliés dont il faut tenir compte afin de mieux résoudre les questions de notre temps.

Mots-clé: Habermas; Rorty; pluralisme dialogique; pragmatisme 